\title{
Fontes e Níveis de Proteína em Rações Iniciais para Leitões Desmamados aos 21 Dias de Idade $^{1}$
}

\author{
Eurípedes Laurindo Lopes ${ }^{2}$, Otto Mack Junqueira ${ }^{3}$, Lúcio Francelino Araújo ${ }^{4}$, Romão da Cunha \\ Nunes $^{2}$, Karina Ferreira Duarte ${ }^{5}$
}

\begin{abstract}
RESUMO - Foi conduzido um experimento com o objetivo de avaliar fontes e níveis de proteína em rações iniciais para leitões desmamados aos 21 dias de idade. Utilizou-se um delineamento inteiramente casualizado em esquema fatorial 2 x 2 x 2 , onde foram estudados os fatores: tipos de dieta (soro de leite em pó e farinha de peixe + lactose), níveis de proteína bruta (20,0\% e 24,0\%) e pesos dos leitões ao desmame $(\leq 6,0$ e $>6,0 \mathrm{~kg})$, totalizando oito tratamentos com quatro repetições cada. O desempenho de leitões desmamados aos 21 dias de idade alimentados com rações contendo farinha de peixe + lactose foi superior ao dos leitões que consumiram apenas o soro de leite em pó. O nível de $24 \%$ de proteína bruta nas rações foi mais eficiente, sobretudo com a combinação farinha de peixe + lactose. Concluiu-se que os tipos de dietas estudados não exerceram efeito sobre os parâmetros histológicos e que a altura das vilosidades é uma função direta do peso do leitão.
\end{abstract}

Palavras-chave: farinha de peixe, lactose, leitões, nível de proteína, soro de leite em pó

\section{Protein Sources and Levels in the Initial Diets for Piglets Weaned at 21 Days of Age}

ABSTRACT - The experiment was conducted to evaluate protein sources and levels in the initial diets, for piglets weaned at 21 days of age. The animals were allotted in a completely randomized design in a factorial $2 \times 2 \times 2$, with type of diets (dried whey and fish meal + lactose), levels of crude protein (20 and 24\%) and piglet weight at weaning ( $\leq 6,0$ and $>6,0 \mathrm{~kg})$, in a total of 8 treatments and four replications each. In the experimental conditions, it can be concluded that among the protein sources tested, the performance of 21 day-age weaned piglets was better for the animals fed fish meal + lactose compared to dried whey. The level of $24 \%$ crude protein was more efficient, mainly in the fish meal + lactose diets. It was concluded that the type of diets studied did not influence the histologycal parameters and the villous height is a direct funcion of piglets weight.

Key Words: dried whey, fish meal, lactose, piglets, protein levels

\section{Introdução}

Visando aumentar o número de leitões terminados por porca/ano, atualmente, há tendência de se reduzir a idade de desmame dos leitões. Nos últimos 25 anos, a idade de desmame foi reduzida de oito para cerca de três semanas, acarretando uma série de problemas fisiológicos e nutricionais para estes animais, Conseqüentemente, a alimentação adequada de leitões na fase pós-desmame é um desafio para o nutricionista e um problema para o suinocultor, em decorrência dos distúrbios que ocorrem na fase de criação.

O desmame aos 21 dias de idade tem mostrado resultados bastante variáveis e exige alternativas para alimentação dos leitões nesta fase. A diarréia após o desmame, o baixo índice de crescimento e o baixo consumo de ração foram citados por Tardin (1985) como os problemas básicos decorrentes do desmame de leitões aos 21 dias de idade.

Os níveis de proteína utilizados nesta fase, além dos tipos de ingredientes para formular dietas para leitões desmamados com três semanas de idade, são bastante discutidos entre os pesquisadores. O baixo desempenho após o desmame, mesmo quando os animais são criados em boas condições sanitárias, é atribuído ao baixo consumo de ração.

Pesquisando o efeito de dietas contendo $25 \%$ de soro de leite em pó, ou 15\% de leite desnatado em pó, comparadas a uma dieta basal composta de milho, aveia, farelo de soja e solúveis de peixe, Graham et al. (1981) mostraram que, mantendo o nível de 20\% de

\footnotetext{
1 Parte da Tese de Doutorado do primeiro autor. FAPESP Proc. 99/7374-6

2 Docentes Departamento de Produção Animal EV/UFG. E.mail: ellopes@vet.ufg.br, romao@vet.ufg.br

3 Docente Departamento de Zootecnia FCAVJ/UNESP. E.mail: ottomack@fcav.unesp.br

4 Docente Departamento de Zootecnia FZEA/USP. E.mail: Ifaraujo@usp.br

5 Mestranda Departamento de Zootecnia FCAVJ/UNESP. E.mail: kafedu@hotmail.com
} 
proteína bruta nas dietas e avaliando os leitões com quatro e seis semanas de idade, as rações com produtos lácteos, sobretudo aquelas com soro seco, melhoraram o desempenho no período de duas semanas pósdesmame; entretanto, os resultados foram semelhantes quando os animais receberam as mesmas dietas por 42 dias.

Crenshaw et al. (1986), ao estudarem dietas simples (milho, farelo de soja) e complexas (milho, farelo de soja, soro de leite em pó, leite desnatado em pó, farinha de peixe e gordura), não verificaram diferenças significativas entre os tipos de dietas para ganho, consumo e conversão alimentar, no período de 24 dias após o desmame aos 21 dias de idade (peso médio de $6,4 \mathrm{~kg}$ ).

O efeito de dietas contendo $22 \%$ de proteína bruta à base de milho, farelo de soja e farinha de peixe em comparação com dietas incluindo 16,2\% e 33,7\% de soro de leite sem a farinha de peixe foi avaliado por Cinq-Mars et al. (1986). Os leitões desmamados com três semanas de idade $(5,0 \mathrm{~kg}$ de peso vivo) que receberam dietas contendo $33,7 \%$ de soro apresentaram melhor desempenho que aqueles alimentados com as demais dietas experimentais, a partir da segunda semana do experimento.

Mahan \& Lepine (1991) realizaram experimento em que tentaram recuperar leitões que, por ocasião do desmame, com idade de 21 a 28 dias, apresentaram atraso no crescimento, principalmente em razão da menor ingestão de leite, graças a um manejo nutricional diferenciado durante a fase inicial. Os animais desmamados com baixo peso $(4,1 \mathrm{~kg}$ a $5,0 \mathrm{~kg})$ responderam melhor às dietas complexas contendo farelo de soja e soro de leite em pó com suplementação de aminoácidos e dextrose. Os autores sugeriram que as rações dos leitões mais pesados por ocasião do desmame $(7,3 \mathrm{~kg}$ a $8,6 \mathrm{~kg}$ ) podem conter menores teores de produtos lácteos e propiciar bom desempenho a esses animais.

Segundo Cline (1992), os leitões nascem com o trato gastrointestinal relativamente imaturo, mas conseguem digerir eficientemente os nutrientes presentes no leite. No desmame, ocorrem mudanças na histologia e morfologia intestinal, tornando a digestão aparentemente comprometida; entretanto, os animais recuperam-se rapidamente, em decorrência dos processos normais de maturação e indução da produção enzimática em resposta aos componentes da dieta. O fornecimento de dietas contendo lactose e proteínas de origem animal reduz a severidade do desafio nutricional imposto pelo desmame precoce.
Efird et al. (1982) avaliaram os efeitos de vários tipos de dieta inicial sobre o desenvolvimento do sistema digestivo de leitões após o desmame aos 21 dias. Os animais que receberam dieta contendo proteína de soja apresentaram maior crescimento do pâncreas, em relação ao peso corporal, que aqueles alimentados com dietas à base de proteínas do leite, o que pode ter decorrido da presença de fatores antinutricionais da soja.

Miller et al. (1986) estudaram a morfologia intestinal em leitões e verificaram que o desmame ocasionou redução na altura das vilosidades e aumento na profundidade das criptas do intestino delgado em leitões desmamados com quatro semanas de idade.

Cera et al. (1988) analisaram as alterações no jejuno de leitões desmamados aos 21 dias de idade e verificaram acentuada redução na altura das vilosidades no terceiro e sétimo dias pós-desmame e que a superfície das vilosidades do intestino delgado foi drasticamente alterada por um período de 7 a 14 dias após o desmame. Por isso, recomendaram o fornecimento de uma dieta de elevado valor nutricional e altamente digestível para os leitões durante os primeiros 14 dias pós desmame, para minimizar os efeitos das alterações digestivas que normalmente ocorrem nesse período.

Dunsford et al. (1989), trabalhando com leitões desmamados aos 21 dias de idade, observaram que os leitões que receberam ração à base de milho e farelo de soja apresentaram vilosidades deformadas, enquanto aqueles que receberam ração à base de farelo de soja, além das vilosidades deformadas, apresentaram também maior espessura da lâmina própria, sugerindo que a inclusão de altas concentrações de farelo de soja (32\% ou 44\%) na ração inicial de leitões acentua as alterações sobre o intestino delgado dos animais.

A escassez de informações de cunho prático que possam resolver os problemas de alimentação, que sérios prejuízos têm causado ao suinocultor, resultou na idéia de se desenvolver o presente trabalho, com o objetivo de avaliar fontes e níveis de proteína em rações iniciais para leitões desmamados aos 21 dias de idade.

\section{Material e Métodos}

Foram utilizados 416 leitões da linhagem Agroceres, desmamados com 21 dias de idade, distribuídos em 32 baias (unidades experimentais), compostas por 13 leitões cada, sendo sete machos e seis fêmeas.

R. Bras. Zootec., v.33, n.6, p.2292-2299, 2004 (Supl. 3) 
O delineamento utilizado foi o inteiramente casualizado em um arranjo fatorial $2 \times 2 \times 2$, onde foram estudados os fatores: tipos de dietas (soro de leite em pó e farinha de peixe+lactose), níveis de proteína bruta (20,0\% e 24,0\%) e pesos dos leitões ao desmame $(\leq 6,0 \mathrm{e}>6,0 \mathrm{~kg})$, totalizando oito tratamentos com quatro repetições cada.

As rações utilizadas foram formuladas à base de milho e farelo de soja, segundo as recomendações de Easter et al. (1994), e a composição dos alimentos, segundo NRC (1998). A composição percentual e os níveis nutricionais calculados das rações experimentais encontram-se nas Tabelas 1 e 2, respectivamente. A ração foi fornecida quatro vezes ao dia, de modo que não houvesse falta, nem fornecimento em excesso, evitando-se o desperdício e estimulando os animais a se alimentarem, com o fornecimento de ração nova, periodicamente.

Para desempenho, as características avaliadas foram o ganho de peso $(\mathrm{kg})$, o consumo de ração $(\mathrm{kg})$ e o índice de conversão alimentar (kg de ração/kg de ganho de peso). Todos os animais foram pesados no início do experimento (21 dias de idade) e no final (42 dias de idade), ocasião em que era realizado o controle do consumo das rações experimentais.

Com relação à morfologia intestinal, avaliaram-se a altura das vilosidades do duodeno (HVILOS), a profundidade das criptas (PCRIP) e a relação vilo:cripta (HVILOS/PCRIP), bem como a relação peso do pâncreas/peso carcaça. Para avaliação destas características foram abatidos aleatoriamente três animais por tratamento, no final do período experimental (42 dias de idade). Após o abate, o pâncreas foi retirado e pesado. Amostras da porção proximal do duodeno, com aproximadamente $1,0 \mathrm{~cm}$ de comprimento, foram colhidas de cada animal. Estas amostras foram abertas em sua borda mesentérica, lavadas, estendidas pela túnica serosa e fixadas em solução de Bouin. Do abate ao início da fixação, o tempo gasto não ultrapassou cinco minutos.

Depois de 24 horas na solução fixadora de Bouin, as amostras foram lavadas em álcool etílico a $70^{\circ} \mathrm{GL}$ e, a seguir, desidratadas em séries crescentes de alcoóis. Após a desidratação, foram recortadas, diafanizadas em benzol e incluídas em parafina, de modo que se obtivessem cortes longitudinais da mucosa intestinal.

Em cada lâmina histológica foram colocados seis cortes semi-seriados com $5 \mathrm{~mm}$ de espessura, sendo que de um corte ao subseqüente foram desprezados seis cortes. Foram feitas três lâminas de cada animal, onde os cortes foram corados segundo a técnica da hematoxilina de Harris-eosina.

Com as lâminas prontas, foram efetuadas 30 medidas de alturas de vilosidades ( $\mathrm{mm}$ ) e 30 de profundidade de criptas (mm) para cada segmento do duodeno

Tabela 1 - Composição centesimal das dietas experimentais

Table 1 - Centesimal composition of the experimental diets

\begin{tabular}{|c|c|c|c|c|}
\hline \multirow{3}{*}{$\begin{array}{l}\text { Ingredientes (\%) } \\
\text { Ingredient } \\
\text { Milho moído (Ground corn) }\end{array}$} & \multicolumn{4}{|c|}{$\begin{array}{c}\text { Dietas experimentais } \\
\text { Experimental diets }\end{array}$} \\
\hline & \multicolumn{2}{|c|}{$\begin{array}{c}\text { Soro } \\
\text { Dried whey }\end{array}$} & \multicolumn{2}{|c|}{$\begin{array}{l}\text { Farinha peixe+lactose } \\
\text { Fish meal + lactose }\end{array}$} \\
\hline & 47,84 & 37,69 & 61,37 & 51,21 \\
\hline Farelo de soja (Soybean meal) & 28,80 & 39,50 & 24,60 & 35,30 \\
\hline Soro de leite em pó (Dried whey) & 20,00 & 20,00 & - & - \\
\hline Lactose (Lactose) & - & - & 5,00 & 5,00 \\
\hline Farinha de peixe (Fish meal) & - & - & 6,00 & 6,00 \\
\hline Suplemento vit+min. ${ }^{1}$ (Vit. and min. supplement) & 0,40 & 0,40 & 0,40 & 0,40 \\
\hline (Salt) & 0,20 & 0,20 & 0,53 & 0,53 \\
\hline Fosfato bicálcico (Dicalcium phosphate) & 1,20 & 1,00 & 0,80 & 0,62 \\
\hline Calcário calcítico (Limestone) & 0,60 & 0,65 & 0,40 & 0,42 \\
\hline L-Lisina (L-Lysine) & 0,43 & 0,14 & 0,40 & 0,12 \\
\hline DL-Metionina (DL-Methionine) & 0,13 & 0,02 & 0,10 & - \\
\hline Óxido de zinco (Zinc oxide) & 0,40 & 0,40 & 0,40 & 0,40 \\
\hline Total & 100,00 & 100,00 & 100,00 & 100,00 \\
\hline
\end{tabular}

${ }^{1}$ Composição por kg de ração (Composition/kg of diet): Vit. A: 4.000UI, Vit. D3: 2.000UI, Vit.E: 35,28 mg, Vit. B1: 0,96 mg, Vit.B2: 5,88 mg, Vit.B12: 25,20 mcg, Vit. K3: 2,24 mg, Ác. Pantotênico (Pantothenic acid): 12,92 mg, Biotina (Biotin): 0,10 mg, Niacina (Niacin): $24,48 \mathrm{mg}$, Colina: 0,56 g, Nitrovin (50\%): 0,24 g, Carbadox (10\%): 0,52 g, lodo: 1,0 g, Se: $148 \mathrm{mg}, \mathrm{Cu}: 125 \mathrm{mg}, \mathrm{Mn}: 60,36 \mathrm{mg}, \mathrm{Fe}:$ $75,60 \mathrm{mg}$, BHT: $120 \mathrm{mg}$, q.s.p.: $1.000 \mathrm{~g}$.

R. Bras. Zootec., v.33, n.6, p.2292-2299, 2004 (Supl. 3) 
Tabela 2 - Níveis nutricionais das dietas experimentais

Table 2 - Nutrition levels of the experimental diets

\begin{tabular}{|c|c|c|c|c|}
\hline \multirow{3}{*}{$\begin{array}{l}\text { Níveis nutricionais (\%) } \\
\text { Nutrition levels } \\
\text { Proteína bruta (\%) (Crude protein) }\end{array}$} & \multicolumn{4}{|c|}{$\begin{array}{l}\text { Dietas experimentais } \\
\text { Experimental diets }\end{array}$} \\
\hline & \multicolumn{2}{|c|}{$\begin{array}{c}\text { Soro } \\
\text { Dried whey }\end{array}$} & \multicolumn{2}{|c|}{$\begin{array}{c}\text { Farinha peixe+lactose } \\
\text { Fish meal + lactose }\end{array}$} \\
\hline & 20,00 & 24,00 & 20,00 & 24,00 \\
\hline Energia digestível (kcal/kg) (Digestible energy) & 3314 & 3318 & 3324 & 3330 \\
\hline Lactose (\%) (Lactose) & 14,40 & 14,40 & 5,00 & 5,00 \\
\hline Cálcio (\%) (Calcium) & 0,82 & 0,82 & 0,82 & 0,82 \\
\hline Fósforo disponível (\%) (Available phosphorus) & 0,43 & 0,42 & 0,43 & 0,41 \\
\hline Sódio (\%) (Sodium) & 0,24 & 0,24 & 0,24 & 0,24 \\
\hline Metionina + cistina total (\%) (Total methionine + cystine) & 0,78 & 0,78 & 0,78 & 0,78 \\
\hline Lisina total (\%) (Total lysine) & 1,53 & 1,53 & 1,53 & 1,53 \\
\hline
\end{tabular}

coletado, o que possibilitou a obtenção da relação HVILOS/PCRIP do duodeno de cada animal.

As medidas de HVILOS foram tomadas a partir da região basal, que coincide com a porção superior das criptas, percorrendo-a longitudinalmente até seu ápice, e as criptas, da sua base até a região de transição cripta-vilosidade.

A análise morfométrica foi realizada em um sistema analisador de imagem da KONTRON ELEKTRONIK(Vídeo Plan), por meio de microscopia de luz, com um aumento de 230 vezes.

Os dados foram analisados utilizando o programa ESTAT (Sistema de Análises Estatísticas, 1994), desenvolvido pelo Departamento de Ciências Exatas da UNESP/FCAV. As médias dos tratamentos foram comparadas pelo teste Tukey a 5\% de probabilidade, segundo as recomendações de Steel \& Torrie (1980).

\section{Resultados e Discussão}

Os valores relativos ao desempenho de leitões desmamados alimentados com diferentes fontes e níveis protéicos no período de 21 a 42 dias são apresentados na Tabela 3. O menor peso dos leitões ao desmame $(\leq 6,0 \mathrm{~kg})$ resultou em animais com menor ganho de peso e consumo de ração comparado àqueles desmamados com peso acima de $6,0 \mathrm{~kg}$. Isto foi observado por Mahan \& Lepine (1991), que verificaram que os menores pesos ao desmame foram determinantes sobre o desempenho das fases subseqüentes, principalmente quando o desmame ocorreu com pesos entre 4,1 e 5,0 kg em comparação aos leitões que começaram a fase inicial com 5,5 a 6,8 kg ou 7,3 a 8,6 kg de peso. Esses dados são semelhantes àqueles encontrados por Bruininx et al. (2001) que trabalharam com três grupos de leitões cujos pesos iniciais foram de 6,7; 7,9 e 9,3 kg e ganhos de peso diário aos 34 dias de idade de 298, 320 e 345 g, respectivamente. Mahan et al. (1998) também constataram que o ganho de peso, independentemente da idade dos animais, é uma função direta do seu peso inicial.

Houve interação significativa $(\mathrm{P}<0,05)$ para ganho de peso entre os fatores tipos de dieta e níveis de proteína bruta. O respectivo desdobramento dos tratamentos evidenciou que a melhor dieta é a associação de farinha de peixe + lactose e $24 \%$ de proteína bruta (Tabela 4). O consumo de ração entre os leitões com peso ao desmame $>6,0 \mathrm{~kg}$ foi superior $(\mathrm{P}<0,05)$ ao dos leitões com menor peso ao desmame. Entretanto não houve diferença $(\mathrm{P}>0,05)$ para este parâmetro entre os tipos de dieta e entre os níveis de 20,0 e $24,0 \%$ de PB. A conversão alimentar foi melhor $(\mathrm{P}<0,05)$ para os animais que receberam ração contendo farinha de peixe mais lactose em relação aos alimentados com soro de leite em pó, ocorrendo o mesmo para os que receberam a dieta com $24,0 \%$ de $\mathrm{PB}$, comparados aos que receberam dieta com 20,0\%. Os melhores resultados foram observados para a combinação de farinha de peixe com lactose, que proporcionou os maiores ganhos de peso quando formuladas com $24 \%$ de PB e melhor conversão alimentar que a ração com soro de leite.

Robles (1993) ponderou que identificar os melhores ingredientes para as dietas dos leitões desmamados deve ser prioridade em qualquer programa de alimentação, considerando-se o preço, a disponibilidade e o valor nutritivo dos alimentos. No entanto, esses auto- 
Tabela 3 - Desempenho de leitões desmamados alimentados com diferentes fontes e níveis protéicos no período de 21 a 42 dias de idade

Table 3 - Piglets performance feeding with different protein sources and levels in the 21 to 42 days of age period

\begin{tabular}{|c|c|c|c|c|c|c|c|}
\hline \multirow[b]{2}{*}{$\begin{array}{l}\text { Parâmetro } \\
\text { Parameter } \\
\end{array}$} & \multicolumn{2}{|c|}{$\begin{array}{c}\text { Peso desmame (kg) } \\
\text { Weight at weaning }\end{array}$} & \multicolumn{2}{|c|}{$\begin{array}{c}\text { Fonte proteína }{ }^{1} \\
\text { Protein source }\end{array}$} & \multicolumn{2}{|c|}{$\begin{array}{c}\text { Nível protéico }^{1}(\%) \\
\text { Protein level } \\
\end{array}$} & \multirow[t]{2}{*}{ CV (\%) } \\
\hline & $<6,0$ & $>6,0$ & $\begin{array}{l}\text { Soro leite } \\
\text { Dried whey }\end{array}$ & $\begin{array}{c}\text { F.peixe+lactose } \\
\text { Fish meal+lactose }\end{array}$ & 20,00 & 24,00 & \\
\hline $\begin{array}{l}\text { Peso inicial (kg) } \\
\text { Initial weight }\end{array}$ & 5,21 & 7,68 & 6,47 & 6,42 & 6,43 & 6,46 & \\
\hline $\begin{array}{l}\text { Peso final (kg) } \\
\text { Final weight }\end{array}$ & 12,44 & 16,46 & 14,34 & 14,56 & 14,22 & 14,68 & \\
\hline $\begin{array}{l}\text { Ganho de peso diário (g) } \\
\text { Daily weight gain }\end{array}$ & $328 b$ & 399a & 356 & 370 & 354 & 373 & 5,26 \\
\hline $\begin{array}{l}\text { Consumo diário de ração (g) } \\
\text { Daily feed intake }\end{array}$ & $619 b$ & 739a & 689 & 669 & 676 & 682 & 5,46 \\
\hline $\begin{array}{l}\text { Conversão alimentar (kg/kg) } \\
\text { Feed conversion }\end{array}$ & 1,89 & 1,85 & $1,93 b$ & $1,81 \mathrm{a}$ & $1,91 b$ & 1,83a & 5,78 \\
\hline
\end{tabular}

Médias seguidas da mesma letra em cada linha dentro de cada fator não diferem $(P>0,05)$ entre si pelo teste Tukey.

1 Interação significativa.

Means followed by the same letters, in the same line, within each factor, are not different $(P>.05)$ by Tukey test.

1 Significant interaction.

Tabela 4 - Interação entre fontes e níveis protéicos para ganho em peso de leitões desmamados, no período de 21 a 42 dias de idade

Table 4 - Sources and levels protein interactions for weight gain of piglets in 21 to 42 days of age period

\begin{tabular}{lcc}
\hline $\begin{array}{l}\text { Fonte protéica } \\
\text { Protein source }\end{array}$ & \multicolumn{2}{c}{$\begin{array}{c}\text { Níveis de proteína (\%) } \\
\text { Protein levels }\end{array}$} \\
\cline { 2 - 3 } & 20,00 & 24,00 \\
\hline $\begin{array}{l}\text { Soro de leite em pó } \\
\text { Dried whey }\end{array}$ & $355 \mathrm{Aa}$ & $360 \mathrm{Ab}$ \\
$\begin{array}{l}\text { Farinha de peixe + lactose } \\
\text { Fish meal + lactose }\end{array}$ & $353 \mathrm{Ba}$ & $387 \mathrm{Aa}$ \\
\hline
\end{tabular}

Médias seguidas da mesma letra minúscula em cada coluna e maiúscula em cada linha não diferem $(P>0,05)$ entre si pelo teste de Tukey.

Means followed by same letters, lowcase in same row and undercase in same line, are not different $(P>.05)$ by Tukey test.

res sugeriram que as dietas dos leitões devem conter ingredientes de maior digestibilidade, como são os produtos lácteos e os derivados de peixe.

Como proposto por Mahan et al. (1993), a lactose seria o dissacarídeo mais limitante para uma ração formulada à base de milho e farelo de soja. Portanto, parece que a combinação destes alimentos tem oferecido os melhores resultados, observando-se neste experimento o melhor ganho de peso pelo efeito do maior nível protéico da ração associado à combinação da farinha de peixe com lactose.

Estudando os melhores níveis de proteína bruta para leitões de 5 a $15 \mathrm{~kg}$ de peso vivo, recebendo rações à base de milho, farelo de soja e leite em pó, Donzele et al. (1992) obtiveram, para esta fase, exigências de 18,63\% PB. Lima et al. (1990) verificaram que os níveis mais adequados foram de $22 \%$ PB para leitões do desmame aos $15 \mathrm{~kg}$ de peso vivo recebendo rações à base de milho e farelo de soja, cujo valor foi exatamente a média entre os níveis protéicos estudados. Embora não fosse realizada análise estatística para o peso final, e sim para o ganho de peso, observou-se média de ganho de peso final $(14,45 \mathrm{~kg}$ ) bastante semelhante àquela obtida por Lima et al. (1990).

As recomendações das principais tabelas de exigências nutricionais ainda oferecem diversas sugestões quanto às necessidades em proteína para a fase pós-desmame. Rostagno et al. (2000) sugerem que os níveis utilizados sejam de $21 \%$ para o período que compreende os pesos entre 6 e $15 \mathrm{~kg}$ de peso, enquanto o NRC (1998) recomenda níveis de 23,7\% de PB, para o intervalo de 5 a $10 \mathrm{~kg}$ de peso, e de 20,9\% de PB, de 10 a $20 \mathrm{~kg}$. Baker (1998), por sua vez, comentando resultados de experimentos desenvolvidos na Universidade de Illinois, sugere para esta fase um esquema de alimentação dividido em três etapas, que compreenderiam os períodos de 7, 14 e 21 dias após o desmame, sendo recomendados pelos autores os níveis de 22, 20 e $18 \%$ de $\mathrm{PB}$, respectivamente.

Com relação às características morfológicas do duodeno (Tabela 5), a maior média de VILOS foi encontrada em leitões de maior peso ao desmame e 
naqueles que receberam a dieta com farinha de peixe + lactose, o mesmo não ocorrendo com os leitões que receberam as rações com os mesmos níveis de proteína bruta. Não houve diferença entre a profundidade das criptas do duodeno dos leitões de diferentes pesos ao desmame, assim como entre os níveis de $\mathrm{PB}(\mathrm{P}>0,05)$. Entretanto, os animais que receberam a ração com farinha de peixe + lactose tiveram maior PCRIP $(\mathrm{P}<0,05)$ que os que receberam a ração contendo soro de leite em pó.

A HVILOS e a PCRIP são afetados diretamente pela qualidade dos ingredientes da ração na fase pósdesmame, principalmente pela sua relação com a quantidade de ração consumida (Cline, 1992). Dunsford et al. (1989) consideraram que os melhores resultados para a digestibilidade dos nutrientes com rações contendo leite ou derivados lácteos, se deve ao equilíbrio da composição do leite, seja pela presença da lactose seja pela seqüência de aminoácidos em sua proteína. Pluske et al. (1996), estudando rações contendo leite de vaca, comprovaram que a atividade enzimática e a capacidade de absorção de nutrientes influenciam os parâmetros morfométricos, sendo que o leite de vaca melhorou o desempenho do animal comparado a rações formuladas apenas à base de proteína da soja.

Observou-se melhor estrutura da mucosa duodenal nos leitões do grupo mais pesado, o que evidencia relação direta entre este parâmetro e o peso do animal.
Embora não tenha sido observado efeito significativo da relação HVILOS/PCRIP, verificou-se tendência de maior relação quando os leitões consumiram a dieta contendo farinha de peixe $+l$ actose, evidenciando melhor combinação da fonte protéica de origem animal com o dissacarídeo em estudo.

Quando os leitões mais pesados consumiram a ração contendo farinha de peixe+lactose, observou-se aumento estatisticamente significativo $(\mathrm{P}<0,05)$ da HVILOS, porém, torna-se difícil discutir o fato de a PCRIP também se apresentar estatisticamente superior $(\mathrm{P}<0,05)$, levando, por essa razão, a resultados semelhantes da relação entre esses dois parâmetros.

Para a característica relação peso do pâncreas/ peso corporal (Tabela 5), não foram observadas diferenças estatísticas significativas $(\mathrm{P}>0,05)$. Registrou-se ainda que a relação peso pâncreas/peso carcaça foi numericamente maior nos leitões do grupo de menor peso ao desmame. Vale salientar que os trabalhos desenvolvidos por diferentes autores mostram que os efeitos são observados principalmente três dias após o desmame. Kelly et al. (1991) constataram que a relação entre o peso do pâncreas e o peso vivo aumenta quando medida aos 3, 5 e 7 dias após o desmame (1,60; 1,93 e 1,99 g de pâncreas/kg de peso vivo, respectivamente). Makkink et al. (1994) verificaram que esta relação foi de 1,53; 1,66; 1,59 e $1,27 \mathrm{~g} / \mathrm{kg}$ em leitões abatidos aos 3 dias após o

Tabela 5 - Morfologia intestinal do duodeno e relação peso do pâncreas/peso da carcaça (PAN/CAR) aos 42 dias de idade de leitões desmamados alimentados com diferentes fontes e níveis de proteína.

Table 5 - Intestinal morphology of duodenum and pancreas weight/carcass weight in 42 days of age, of piglets feeding of sources and levels protein

\begin{tabular}{|c|c|c|c|c|c|c|c|}
\hline \multirow[b]{2}{*}{$\begin{array}{l}\text { Parâmetro } \\
\text { Parameter }\end{array}$} & \multicolumn{2}{|c|}{$\begin{array}{c}\text { Peso desmame }(\mathrm{kg}) \\
\text { Weight at weaning }\end{array}$} & \multicolumn{2}{|c|}{$\begin{array}{c}\text { Fonte proteína } \\
\text { Protein source }\end{array}$} & \multicolumn{2}{|c|}{$\begin{array}{c}\text { Nível protéico }^{1}(\%) \\
\text { Protein level }\end{array}$} & \multirow[t]{2}{*}{ CV (\%) } \\
\hline & $<6,0$ & $>6,0$ & $\begin{array}{l}\text { Soro leite } \\
\text { Dried whey }\end{array}$ & $\begin{array}{l}\text { F.peixe+lactose } \\
\text { Fish meal+lactose }\end{array}$ & 20,00 & 24,00 & \\
\hline $\begin{array}{l}\text { HVILOS }(\mathrm{mm}) \\
\text { Villus height }\end{array}$ & $310,67 b$ & 356,91 a & $305,43 \mathrm{~b}$ & $362,14 \mathrm{a}$ & 319,02 & 348,56 & 15,03 \\
\hline $\begin{array}{l}\text { PCRIP }(\mathrm{mm}) \\
\text { Crypt depth }\end{array}$ & 131,56 & 143,83 & 128,18 a & $147,20 b$ & 131,07 & 144,30 & 14,05 \\
\hline $\begin{array}{l}\text { HVILOS/PCRIP } \\
\text { Villus height/Crypt depth }\end{array}$ & 2,36 & 2,47 & 2,39 & 2,45 & 2,43 & 2,41 & 5,44 \\
\hline $\begin{array}{l}\mathrm{PAN} / \mathrm{CAR}(\mathrm{g} / \mathrm{kg}) \\
\text { Pancreas/carcass }\end{array}$ & $2,14 \mathrm{a}$ & 1,93 a & 1,89 a & 2,13 a & 2,03 a & 1,98 a & 12,96 \\
\hline
\end{tabular}

Médias seguidas da mesma letra em cada linha dentro de cada fator não diferem entre si pelo teste Tukey $(P>0,05)$.

Means followed by same letters, in same line, within each factor, are not different by Tukey test $(P>.05)$.

R. Bras. Zootec., v.33, n.6, p.2292-2299, 2004 (Supl. 3) 
desmame quando receberam leite em pó, proteína isolada de soja, farinha de peixe e farelo de soja, respectivamente, observando que este grupo apresentou valores significativamente menores, porém aos seis dias essas diferenças desapareceram.

Não foram verificadas interações significativas dos dados referentes à morfologia intestinal do duodeno, tampouco para a relação peso do pâncreas/ peso da carcaça.

Outras combinações de ingredientes, sobretudo daqueles de alta digestibilidade e elevado valor nutricional, precisam ser avaliadas para a alimentação dos leitões no período pós-desmame. Desenvolver outros estudos com alternativas nutricionais, seus níveis de inclusão e suas limitações constitui importante linha de pesquisa para nutrição e alimentação de suínos.

\section{Conclusões}

O ganho de peso diário é uma função direta do peso inicial dos animais. A conversão alimentar de leitões desmamados aos 21 dias de idade foi melhor nos leitões que receberam a ração contendo farinha de peixe + lactose que naqueles que consumiram a ração contendo apenas o soro de leite em pó. Para os níveis de proteína, observou-se que $24 \%$ PB nas rações foi mais eficiente, sobretudo com a combinação farinha de peixe + lactose.

\section{Literatura Citada}

BAKER, D.H. Nutrient allowances for swine. Feedstuffs, v.70, n.30, p.40-44, 1998.

BRUININX, E.M.A.M.; van der PEET-SCHWERING, C.M.C.; SCHRAMA, J.W. et al. Individually measured feed intake characteristics and growth performance of group-housed wealing pigs: Effects of sex, initial body weight, and body weight distribution within groups. Journal of Animal Science, v.79, n.2, p.301-308, 2001.

CERA, K.R.; MAHAN, D.C.; CROSS, R.F. et al. Effect of age weaning and postweaning diet on small intestinal growth and jejunal morphology in young swine. Journal of Animal Science, v.66, n.2, p.574-84, 1988.

CINQ-MARS, D.; BELANGER, G.; LACHANCE, B. et al. Performance of early weaned piglets fed diets containing various amounts of whey protein concentrate. Journal of Animal Science, v.63, n.1, p.145-50, 1986.

CLINE, T.R. Development of the digestive physiology of baby pigs and the use of supplemental enzimes in their diets. In: SIMPÓSIO DO COLÉGIO BRASILEIRO DE NUTRIÇÃO ANIMAL, 7., 1992, Campinas. Anais... Campinas: Colégio Brasileiro de Nutrição Animal, 1992. p.149-61.

CRENSHAW, T.D.; COOK, M.E.; ODLE, J. et al. Effect of nutritional status, age at weaning and room temperature on growth and systemic immune response of weaninling pigs. Journal of Animal Science, v.63, n.6, p.1845-53, 1986.
DONZELE, J.L.; COSTA, P.M.A.; ROSTAGNO, H.S. et al. Níveis de proteína bruta para suínos de 5 a $15 \mathrm{~kg}$. Revista Brasileira de Zootecnia, v.21, n.6, p.1077-83, 1992.

DUNSFORD, B.R.; KNABE, D.A.; HAENSLY, W.E. Effect of dietary soybean meal on the microscopic anatomy of the small intestine in the early weaned pig. Journal of Animal Science, v.67, n.7, p.1855-1863, 1989.

EASTER, R.A.; ODLE, J.; HOLLIS, G.R. et al. Dietary nutrient allowances for swine. Feedstuffs, v.66, n.30, p.40-46, 1994.

EFIRD, R.C.; ARMSTRONG, W.D.; HERMAN, D.L. The development of digestive capacity in young pigs: Effects of weaning regimen and dietary treatment. Journal of Animal Science, v.55, n.6, p.1370-1379, 1982.

GRAHAM, P.L.; MAHAN, D.C.; SHIEDS, R.G. Effect of starter diet and length of feeding regimen on performance and digestive enzyme activity of 2-week old weaned pigs. Journal of Animal Science, v.53, n.2, p.299-307, 1981.

JUNQUEIRA, O.M. Alternativas para produtos lácteos em rações iniciais para suínos. In: MINI-SIMPÓSIO DO COLÉGIO BRASILEIRO DE NUTRIÇÃO ANIMAL, 5., 1991, Campinas. Anais... Campinas: Colégio Brasileiro de Nutrição Animal, 1991. p.53-70.

KELLY, D.; SMYTH, J.A.; McCRACKEN, K.J. Digestive development of the early-weaned pig. 2. Effect of level of food intake on digestive enzyme activity during the immediate post-weaning period. British Journal of Nutrition, v.65, n.1, p.181-188, 1991.

LIMA, J.A.F.; BETERCHINI, A.G.; OLIVEIRA, A.I.G. et al. Efeito da idade de desmame sobre as exigências de proteína bruta para leitões na fase pré-inicial (desmame a 15 kg PV). Revista da Sociedade Brasileira de Zootecnia, v.19, n.5, p.362-369, 1990.

MAHAN, D.C.; CROMWELL, G.L.; EWAN, R.C. et al. Evaluation of the feeding of a phase 1 nursery diet to threeweek-old pigs of two weanuni weights. Journal of Animal Science, v.76, n.3, p.578- 583, 1998.

MAHAN, D.C.; EASTER, R.A.; CROMWELL, G.L. et al. Effect of dietary lysine levels formulated by altering the ratio of corn:soybean meal with or without dried whey and L-lysine. $\mathrm{HCl}$ in diets for weanling pigs. Journal of Animal Science, v.71, n.7, p.1848-52, 1993.

MAHAN, D.C.; LEPINE, A.J. Effect of pig weaning weight and associated nursery feeding programs on subsequent performance to 105 kilograms body weight. Journal of Animal Science, v.69, n.4, p.1370-1378, 1991.

MAKKINK, C.A.; NEGULESCU, G.P.; QIN, G.X. et al. Effect of dietary protein source on feed intake, growth, pancreatic enzyme activities and jejunal morphology in newly-weaned piglets. British Journal Nutrition, v.72, n.2, p.353-368, 1994.

MILLER, B.G.; WHITTEMORE, C.T.; STOKES, C.R. et al. Effect of weaning on the capacity of pigs intestinal villi to digest and absorb nutrients. Journal of Agriculture Science, v.107, n.3, p.579-589, 1986.

NATIONAL RESEARCH COUNCIL - NRC. Nutrients requirements of swine, 10.ed. Washington: National Academy of Science, 1998. 189p.

PLUSKE, J.R.; WILLIAMS, I.H.; AHERNE, F.X. Villous height and crypt depth in piglets in response to increases in the intake of cows' milk after weaning. Animal Science, v.62, n.1, p.145-158, 1996.

ROBLES, A. Alimentación del lechon. In: MINI-SIMPÓSIO DO COLÉGIO BRASILEIRO DE NUTRIÇÃO ANIMAL, 10.,

R. Bras. Zootec., v.33, n.6, p.2292-2299, 2004 (Supl. 3) 
1993, Valinhos. Anais... Campinas: Colégio Brasileiro de Nutrição Animal, 1993. p.83-100.

ROSTAGNO, H.S.; ALBINO, L.F.T.; DONZELE, J.L. et al. Composição de alimentos e exigências nutricionais de aves e suínos (tabelas brasileiras). Viçosa, MG: Universidade Federal de Viçosa, 2000. 141p.

STEEL, R.G.D.; TORRIE, J.H. Principles and procedures of statistics. 2.ed. New York: McGraw-Hill Book Company, 1980. 633p.
TARDIN, A.C. Fisiologia digestiva e nutrição no desmame precoce de leitões. In: CONGRESSO DA ASSOCIAÇÃO BRASILEIRA DE VETERINÁRIOS ESPECIALISTAS EM SUÍNOS, 2., 1985, Rio de Janeiro. Anais.... Rio de Janeiro: Associação Brasileira de Veterinários Especialistas em Suínos, 1985. p.33-57.

Recebido em: 10/02/03

Aceito em: 23/09/04 